\title{
FAKTOR RESIKO KEJADIAN DIABETES MELITUS TIPE 2 DI PUSKESMAS PURWOKERTO SELATAN KABUPATEN BANYUMAS
}

\author{
Fasikhatul Qomariyah $^{1 *}$, Peppy Octaviani ${ }^{1}$, Rani Prabandari $^{1}$ \\ ${ }^{1}$ Universitas Harapan Bangsa, Purwokerto, Indonesia \\ *corresponding author \\ Email: fasikhatulqomariyah@gmail.com
}

Diterima : 23 September 2021

Direvisi : 11 Oktober 2021

Publikasi : 20 Oktober 2021

doi:10.52216/jfsi.vol4no2p79-84

\begin{abstract}
Diabetes Mellitus (DM) type 2 is a metabolic disease characterized by an increase in blood sugar levels caused by a decrease in insulin secretion or insulin function disorders. The purpose of this study was to determine the risk factors for type 2 diabetes melitus based on age, gender, obesity, physical activity, smoking habits in the South Purwokerto Public Health Center, Banyumas Regency. The method used was quqnitative prospectively using a correlation description design or design with a cross sectional approach. The results of this study using the charactristics of the respondents showed that of the 64 patients the majority of the respondents were aged in the adult category (20-60 years) as many as 34 people $(53,1 \%)$ and again in the elderly category (> 60 years) as many as 30 people $(46,9 \%)$ and none of the respondents wre in the adolescent category (11-19 yeras). Most of the respondents were female as many as 48 people $(75,0 \%)$ while 26 the male sex was 16 people $(25,0 \%) 38$ respondents $(59,6 \%)$ were not obese, while 26 respondents were obese (40,6\%). Activity physical of category as many as 26 people $(40,6 \%)$ moderate physical activity as many 20 people $(68,8 \%)$. The amount of the respondents who smoked wre 23 people (35,9\%) and there was a relationship between the risk factors of age, gender, obesity, physical activity, smoking habit with type 2 diabetes melitus.
\end{abstract}

Keywords: Type 2 Diabetes Melitus. South Purwokerto Public Health Center

\section{Intisari}

Diabetes Melitus (DM) tipe 2 merupakan sebuah penyakit metabolik yang ditandai dengan adanya kenaikan kadar gula dalam darah yang disebabkan adanya penurunan sekresi insulin atau adanya gangguan fungsi insulin. Tujuan penelitian ini untuk mengetahui faktor risiko diabetes melitus tipe 2 berdasarkan usia, jenis kelamin, obesitas, aktivitas fisik, kebiasaan merokok di Puskesmas Purwokerto Selatan Kabupaten Banyumas. Metode yang digunakan kuantitatif secara prospektif menggunakan rancangan atau desain deskripsi korelasi dengan pendekatan cross sectional. Hasil penelitian ini menggunakan karakteristik responden menunjukkan bahwa dari 64 pasien mayoritas bahwa usia responden memiliki usia pada kategori dewasa (20-60 tahun) sebanyak 34 orang (53,1\%) dan usia pada kategori lanjut usia (> 60 tahun) sebanyak 30 orang (46,9\%) dan tidak ada responden yang usia pada kategori remaja (11-19 tahun). Responden sebagian besar berjenis kelamin perempuan sebanyak 48 orang (75,0\%), sedangkan jenis kelamin laki-laki sebanyak 16 orang (25,0\%). Responden yang tidak obesitas sebanyak38 orang (59,4\%), sedangkan responden obesitas sebanyak26 orang (40,6\%). Aktivitas fisik responden sebagian pada kategori tinggi sebanyak 44 orang (68,8\%), dan aktivitas sedang sebanyak 20 orang (31,3\%). Responden sebagian besar tidak merokok sebanyak 41 orang $(64,1 \%)$, sedangkan responden yang merokok sebanyak 23 orang $(35,9 \%)$ dan terdapat hubungan faktor risiko usia, jenis kelamin, obesitas, aktivitas fisik, kebiasaan merokok diabetes melitus tipe 2. 


\section{Pendahuluan}

Diabetes melitus (DM) adalah penyakit yang terjadi karena adanya gangguan metabolisme secara kronis dengan ditandai adanya peningkatan gula darah (hiperglikemia) yang disebabkan oleh adanya ketidakseimbangan antara kebutuhan dengan suplai. Fungsi insulin dalam tubuh adalah sebagai kunci bagi glukosa yang ada dalam sel agar bisa digunakan untuk pertumbuhan.

Pengelompokan Diabetes Melitus sesuai dengan etiologi dan gejala yang diderita dibagi menjadi 4 yaitu: DM tipe 1, DM tipe 2, DM gastrointestinal dan DM spesifik lainnya. Dengan DM tipe 2 merupakan tipe DM yang sangat sering terjadi.

Berdasarkan (Dinkes Banyumas, 2020)data jumlah penderita diabetes melitus di Kabupaten Banyumas sebanyak 25.744 yang mendapat pelayanan kesehatan sesuai standar sebanyak 24.600 atau sebesar 95,6\%. Di Indonesia terdapat penderita diabetes melitus sebanyak 1785 pasien yang memiliki komplikasi nefropati $(7,3 \%)$, luka kaki diabetes (15\%), makrovaskular (16\%), retinopati $(42 \%)$ dan yang paling besar adalah neuropati $(63,5 \%)$.

Penelitian oleh (Kabosu et al, 2019)tentang "Faktor Risiko Kejadian diabetes melitus tipe 2 di RS Bhayangkara Kota Kupang" dilakukan pada penderita DM tipe 2 yang menjalani pengobatan rawat jalan di RS Bhayangkara Kupang didapatkan bahwa faktor-faktor risiko kejadian diabetes melitus tipe 2 di RS Bhayangkara Kota Kupang yaitu usia, obesitas, hipertensi, pola konsumsi, stres.

Tingginya angka kejadian diabetes melitus membuat angka harapan hidup manusia menjadi lebih buruk. Banyaknya kasus kejadian diabetes melitus dipengaruhi oleh beberapa faktor antara lain seperti genetik, usia, jenis kelamin, obesitas merokok dan gaya hidup. Pada umumnya penderita DM pada orang dewasa termasuk dalam DM tipe 2 dan diketahui dari sebagian jumlah tersebut adalah penderita yang berumur $\geq 60$ tahun (Evi \& Yanita, 2016).
Berlandaskan uraian dan kejadian atau fenomena yang terjadi maka peneliti tertarik untuk meneliti tentang "Faktor Risiko Kejadian Diabetes Melitus Tipe 2 di Puskesmas Selatan Kabupaten Banyumas"

\section{Metode Penelitian}

\subsection{Rancangan Penelitian}

Merupakan penelitian kuantitatif dan desain yang digunakan Deskriptif Korelatif serta pendekatan waktu yang digunakan adalah Cross Sectional. Serta lokasi dilakukannya penelitian ini bertepatan di Puskesmas Purwokerto Selatan Kabupaten Banyumas yang dilaksanakan sesuai dengan rencana jadwal penelitian yaitu pada bulan Juni.

Populasi dalam penelitian ini diambil dari jumlah penderita DM tipe 2 yang bertempat tinggal di wilayah Kerja Puskesmas Purwokerto Selatan yang berjumlah 75 responden dengan teknik Total sampling.

Variabel independen dalam penelitian ini yaitu usia, obesitas, jenis kelamin serta merokok. Sedangkan, variabel dependennya adalah Kejadian DM tipe 2. Instrumen yang digunakan berupa kuesioner dan alat ukur berat badan dan tinggi badan responden.

\subsection{Analisis Data}

Analisa data menggunakan Univariate dan Bivariate. Analisa Univariate guna mengetahu persentase dari setiap variabel dan analisa Bivariat dalam penelitian ini memakai Chi Square yang bertujuan untuk mengetahui hubungan antar variabel bila datanya mempunyai skala ukur nominal by nominal (Sugiyono, 2012).

\section{Hasil dan Pembahasan}

\subsection{Karakteristik responden}

Pada tabel 1 diperoleh hasil separuh lebih responden berusia dewasa $(20-60$ tahun $)$ sebanyak $34(53,1 \%)$ responden, berjenis kelamin perempuan sebanyak $48(75,0 \%)$, tidak obesitas sebanyak 38 orang $(59,4 \%)$, Aktivitas fisik tinggi 
sebanyak $44 \quad(68,8 \%)$ dan tidak merokok sebanyak $41(64,1 \%)$ responden.

Tabel 1. Distribusi frekuensi karakteristik responden

\begin{tabular}{|c|c|c|}
\hline Karakteristik Responden & $\mathbf{F}$ & $\%$ \\
\hline \multicolumn{3}{|l|}{ USIA } \\
\hline Remaja (11 - 19 tahun) & 0 & 0,0 \\
\hline Dewasa $(20-60$ tahun $)$ & 34 & 53,1 \\
\hline Lanjut Usia (> 60 tahun) & 30 & 46,9 \\
\hline \multicolumn{3}{|l|}{ JENIS KELAMIN } \\
\hline Perempuan & 48 & 75,0 \\
\hline Laki-laki & 16 & 25,0 \\
\hline \multicolumn{3}{|l|}{ OBESITAS } \\
\hline Tidak Obesitas $\left(\right.$ IMT $\left.<25 \mathrm{~kg} / \mathrm{m}^{2}\right)$ & 38 & 59,4 \\
\hline Obesitas $\left(\mathrm{IMT} \geq 25 \mathrm{~kg} / \mathrm{m}^{2}\right)$ & 26 & 40,6 \\
\hline \multicolumn{3}{|l|}{ AKTIFITAS FISIK } \\
\hline Rendah $(<600)$ & 0 & 0,0 \\
\hline Sedang $(3000>$ MET $\leq 600)$ & 20 & 31,3 \\
\hline Tinggi $(\geq 3000)$ & 44 & 68,8 \\
\hline \multicolumn{3}{|l|}{ KEBIASAAN MEROKOK } \\
\hline Tidak Merokok & 41 & 64,1 \\
\hline Merokok & 23 & 35,9 \\
\hline Total & 64 & 100,0 \\
\hline
\end{tabular}

\subsection{Kejadian DM Tipe 2}

. Dilihat dari tabel 2 dapat diketahui bahwa sebagian besar responden mengalami kejadian DM tipe 2 sebesar 39 responden $(60,9 \%)$ dan responden yang tidak mengalami DM tipe 2 sebesar 25 responden $(39,1 \%)$.

Tabel 2. Distribusi frekuensi kejadian DM Tipe 2

\begin{tabular}{|c|c|c|}
\hline \multirow{2}{*}{\multicolumn{3}{|c|}{$\frac{\text { Variabel }}{\text { KEJADIAN DM TIPE } 2}$}} \\
\hline & & \\
\hline Ya & 39 & 60,9 \\
\hline Tidak & 25 & 39,1 \\
\hline Total & 64 & 100,0 \\
\hline
\end{tabular}

3.3. Hubungan dan faktor risiko usia terhadap kejadian DM tipe 2 di Puskesmas Purwokerto Selatan

Dari tabel 3 dapat diketahui bahwa paling banyak responden berumur lanjut usia (> 60 tahun) yang mengalami kejadian DM tipe 2 sebanyak $29(45,3 \%)$ responden dan pada responden yang umurnya masuk dalam kategori dewasa (20-60 tahun) sebanyak 20 responden $(15,6 \%)$. Hasil uji Chi Square diperoleh $p$ - value $0,000<0,05$ yang mengartikan adanya hubungan antara usia dengan kejadian DM tipe 2.

Tabel 3. Uji Chi Square: Hubungan usia terhadap kejadian DM tipe 2 di Puskesmas Purwokerto Selatan

\begin{tabular}{|c|c|c|c|c|c|c|c|}
\hline \multirow{3}{*}{ Usia } & \multicolumn{7}{|c|}{ Kejadian DM Tipe 2} \\
\hline & \multicolumn{2}{|c|}{ Ya } & \multicolumn{2}{|c|}{ Tidak } & \multicolumn{2}{|c|}{ Total } & \multirow{2}{*}{$\begin{array}{c}\text { Sig. } \\
\text { (p-value) }\end{array}$} \\
\hline & $\mathrm{f}$ & $\%$ & $\mathrm{f}$ & $\%$ & $\mathrm{f}$ & $\%$ & \\
\hline $\begin{array}{l}\text { Remaja } \\
(11-19 \\
\text { tahun) }\end{array}$ & 0 & 0,0 & 0 & 0,0 & 0 & 0,0 & \\
\hline $\begin{array}{l}\text { Dewasa } \\
(20-60 \\
\text { tahun) }\end{array}$ & 10 & $\begin{array}{c}15, \\
6\end{array}$ & $\begin{array}{l}2 \\
4\end{array}$ & 37,5 & 34 & 53,1 & 0,000 \\
\hline $\begin{array}{l}\text { Lanjut } \\
\text { Usia (> } \\
60 \text { tahun) }\end{array}$ & 29 & $\begin{array}{c}45, \\
3\end{array}$ & 1 & 1,6 & 30 & 46,9 & \\
\hline
\end{tabular}

Hasil ini sejalan dengan(Fanani, 2020) didapatkan bahwa dari 52 orang responden yang berumur $\geq 40$ tahun diketahui 40 orang $(76,9 \%)$ responden menderita diabetes melitus tipe II dan 9 orang $(17,3 \%)$ responden menderita diabetes melitus tidak tipe II, sedangkan responden yang berumur $<40$ tahun diketahui $1(1,9 \%)$ responden.

Tabel 4. Nilai Odds Ratio (OR): Faktor risiko usia terhadap kejadian diabetes melitus tipe 2 di Puskesmas Purwokerto Selatan

\begin{tabular}{cccc}
\hline Variabel & $\begin{array}{c}\text { Nilai } \text { Odds } \\
\text { Ratio }\end{array}$ & \multicolumn{2}{c}{ 95\% C.I for $\operatorname{Exp}(\boldsymbol{B})$} \\
\cline { 3 - 4 } & $\operatorname{Exp}(\boldsymbol{B})$ & Lower & Upper \\
\hline Usia & 0,014 & 0,002 & 0,120 \\
\hline
\end{tabular}

Tabel 4 dapat dijelaskan bahwa faktor risiko usia terhadap kejadian DM tipe 2 diketahui dari nilai Odds Ratio (OR) yang ditunjukkan pada nilai $\operatorname{Exp}(B)$ yaitu 0.014 yang artinya bahwa usia mempunyai pengaruh sebesar 0,014 kali kepada kejadian DM. Secara teori dinyatakan bahwa usia memiliki hubungan yang begitu erat dengan kenaikan gula darah, sehingga semakin bertambahnya usia maka persentase kejadian DM dan gangguan glukosa meningkat. Proses menua yang terjadi pada usia $\geq 45$ tahun menyebabkan penurunan anatomi, fisiologi, biokimia tubuh yang berdampak pada resistensi insulin (PERKENI, 2015).

3.4. Hubungan dan faktor risiko jenis kelamin terhadap kejadian diabetes melitus tipe 2 di Puskesmas Purwokerto Selatan 
Tabel 5. Uji Chi Square: Hubungan jenis kelamin terhadap kejadian diabetes melitus Tipe 2 di Puskesmas Purwokerto Selatan

\begin{tabular}{lccccccc}
\hline \multirow{2}{*}{$\begin{array}{c}\text { Jenis } \\
\text { Kelamin }\end{array}$} & \multicolumn{6}{c}{ Yejadian DM Tipe 2 } \\
\cline { 2 - 7 } & $\mathbf{F}$ & $\mathbf{\%}$ & $\mathbf{F}$ & $\boldsymbol{\%}$ & $\mathbf{f}$ & $\mathbf{\%}$ & Sig. \\
& (p-value $)$ \\
\hline Perempuan & 23 & 35,9 & 25 & 39,1 & 48 & 75,0 & \multirow{2}{*}{0,000} \\
Laki-laki & 16 & 25,0 & 0 & 0,0 & 16 & 25,0 & \\
\hline
\end{tabular}

Tabel 5 menunjukkan responden berjenis kelamin perempuan yang mengalami kejadian DM tipe 2 sebanyak $23(35,9 \%)$ responden, sedangkan yang tidak mengalami kejadian DM tipe 2 sebanyak 25 orang $(39,1 \%)$. Responden berjenis kelamin laki-laki semua mengalami kejadian DM tipe 2 sebanyak 16 orang $(25,0 \%)$. Hasil uji $C h i$ Square diperoleh hasil $p$-value $=0,000(<\alpha=$ $0,05)$.

Sejalan penelitiannya (Kabosu et al, 2019)bahwa didapatkan responden yang memiliki jenis kelamin perempuan memiliki risiko 1,749 kali lebih besar dibanding dengan responden lakilaki. Dari hasil wawancara pada penderita DM tipe dua yang berjenis kelamin perempuan didapatkan informasi bahwa kejadian ini disebabkan karena responden perempuan memiliki kolesterol jahat atau LDL lebih tinggi dibanding dengan responden laki- laki. Kemudian, antara responden pria dan wanita terdapat perbedaan gaya hidup dan activity daily living (ADL).

Tabel 6. Nilai Odds Ratio (OR): Faktor risiko jenis kelamin terhadap kejadian diabetes melitus tipe 2 di Puskesmas Purwokerto Selatan

\begin{tabular}{cccc}
\hline \multirow{2}{*}{ Variabel } & $\begin{array}{c}\text { Nilai } \text { Odds } \\
\text { Ratio }\end{array}$ & \multicolumn{2}{c}{ 95\% C.I for $\operatorname{Exp}(\boldsymbol{B})$} \\
\cline { 3 - 4 } & $\boldsymbol{E x p}(\boldsymbol{B})$ & Lower & Upper \\
\hline Jenis & 0,010 & 0,000 & 0,120 \\
Kelamin & & & \\
\hline
\end{tabular}

Tabel 6 menjelaskan bahwa faktor risiko jenis kelamin terhadap kejadian DM tipe 2 diketahui dari nilai Odds Ratio (OR) yang ditunjukkan pada nilai $\operatorname{Exp}(B)$ yaitu 0.010 yang artinya bahwa jenis kelamin mempunyai pengaruh sebesar 0,010 kali lipat terhadap kejadian DM tipe 2.

3.5. Hubungan dan faktor risiko obesitas terhadap kejadian Diabetes Melitus Tipe 2 di Puskesmas Purwokerto Selatan.
Dari tabel 4.7 diperoleh hasil responden tidak obesitas dan mengalami DM tipe 2 ada 27 $(42,2 \%)$ responden. Sedangkan, tidak mengalami kejadian DM tipe 2 sebanyak $11 \quad(17,2 \%)$ responden. Responden obesitas dan mengalami DM tipe 2 ada $12(18,8 \%)$ responden, sedangkan yang tidak mengalami kejadian diabetes melitus tipe 2 sebanyak 14 orang $(21,9 \%)$. Uji Chi Square didapatkan $p$-value $=0,045<0,05$. Artinya ada hubungan obesitas dengan kejadian DM tipe 2.

Tabel 7. Uji Chi Square: Hubungan obesitas terhadap kejadian diabetes melitus tipe 2 di Puskesmas Purwokerto Selatan

\begin{tabular}{|c|c|c|c|c|c|c|c|c|}
\hline \multirow{3}{*}{ Obesitas } & \multicolumn{8}{|c|}{ Kejadian DM Tipe 2} \\
\hline & \multicolumn{2}{|c|}{ Ya } & \multicolumn{2}{|c|}{ Tidak } & \multicolumn{2}{|c|}{ Total } & \multirow{2}{*}{\multicolumn{2}{|c|}{$\underset{(p-v a l u e)}{\text { Sig. }}$}} \\
\hline & $\mathbf{F}$ & $\%$ & $\mathbf{F} \quad \mathbf{c}$ & $\%$ & $\mathbf{f}$ & $\%$ & & \\
\hline \multirow{2}{*}{$\begin{array}{l}\text { Tidak } \\
\text { Obesitas } \\
\text { Obesitas }\end{array}$} & 27 & 42,2 & 11 & & & 38 & 59,4 & \multirow{2}{*}{0,045} \\
\hline & 12 & 18,8 & 14 & & & 26 & 40,6 & \\
\hline
\end{tabular}

Didukung oleh penelitiannya (Kabosu et al, 2019)yang didapatkan hasil perhitungan Odds Ratio (OR) sebesar 3,826 yang menerangkan bahwa responden dengan obesitas memiliki risiko 3,8 kali lebih besar dibanding dengan responden yang tidak obesitas.

Tabel 8. Nilai Odds Ratio (OR): Faktor risiko obesitas terhadap kejadian diabetes melitus tipe 2 di Puskesmas Purwokerto Selatan

\begin{tabular}{cccc}
\hline Variabel & $\begin{array}{c}\text { Nilai } \text { Odds } \\
\text { Ratio }\end{array}$ & \multicolumn{2}{c}{ 95\% C.I for $\operatorname{Exp}(\boldsymbol{B})$} \\
\cline { 3 - 4 } & Exp $(\boldsymbol{B})$ & Lower & Upper \\
\hline Obesitas & 2,864 & 1,010 & 8,119 \\
\hline
\end{tabular}

Berdasarkan tabel 4.8 dapat dijelaskan bahwa faktor risiko obesitas terhadap kejadian DM tipe 2 diketahui dari nilai Odds Ratio (OR) yang ditunjukkan pada nilai $\operatorname{Exp}(B)$ yaitu 2,864 yang artinya bahwa obesitas mempunyai pengaruh sebesar 2,864 kali terhadap kejadian diabetes melitus tipe 2.Kegemukan merupakan masalah yang umum terjadi. Banyak faktor penyebab terjadinya kegemukan ini baik dari dalam maupun luar.

3.6. Hubungan dan faktor risiko aktivitas fisik terhadap kejadian diabetes melitus tipe 2 di Puskesmas Purwokerto Selatan

Tabel 9 menjelaskan bahwa sebagian besar responden yang memiliki aktivitas fisik dalam katagori tinggi yang tidak mengalami kejadian 
DM tipe 2 sebanyak $44(68,8 \%)$ responden, memiliki aktivitas fisik dalam kategori tinggi yang mengalami kejadian DM tipe 2. Uji Chi Square didapatkan $p$-value $=0,001<0,05$ artinya terdapat hubungan aktivitas fisik terhadap kejadian diabetes melitus tipe 2 .

Tabel 9. Uji Chi Square: Hubungan aktivitas fisik terhadap kejadian DM tipe 2 di Puskesmas Purwokerto Selatan

\begin{tabular}{ccccccccc}
\hline \multirow{2}{*}{$\begin{array}{c}\text { Aktivitas } \\
\text { Fisik }\end{array}$} & \multicolumn{6}{c}{ Kejadian DM Tipe 2 } \\
\cline { 2 - 7 } & \multicolumn{2}{c}{ Ya } & \multicolumn{4}{c}{ Tidak } & \multicolumn{3}{c}{ Total } & \multirow{2}{*}{$\begin{array}{c}\text { Sig. } \\
\text { (p-value })\end{array}$} \\
\hline Rendah & 0 & 0,0 & 0 & 0,0 & 0 & 0,0 & \\
Sedang & 18 & 28,1 & 2 & 3,1 & 20 & 31,2 & 0,001 \\
Tinggi & 21 & 32,8 & 23 & 35,9 & 44 & 68,8 & \\
\hline
\end{tabular}

Sejalan dengan hasil penelitiannya (Aune et $a l, 2015)$ menjelaskan bahwa aktivitas fisik dalam kategori tinggi berhubungan dengan penurunan risiko DM tipe 2. Selain itu aktivitas fisik lain seperti aktivitas di waktu luang, intensitas rendah, pekerjaan dan aktivitas kebugaran jasmani berhubungan dengan penurunan kejadian DM tipe 2 sebesar $25-40 \%$.

Tabel 10. Nilai Odds Ratio (OR): faktor risiko aktivitas fisik terhadap kejadian diabetes melitus tipe 2 di Puskesmas Purwokerto Selatan Kabupaten Banyumas

\begin{tabular}{cccc}
\hline Variabel & $\begin{array}{c}\text { Nilai } \text { Odds } \\
\text { Ratio } \\
(\boldsymbol{B})\end{array}$ & \multicolumn{2}{c}{$\mathbf{9 5 \%}$ C.I for $\operatorname{Exp}(\boldsymbol{B})$} \\
\hline Aktivitas & 9,857 & 2,038 & Upper \\
Fisik & & & 47,670 \\
\hline
\end{tabular}

3.7. Hubungan dan Faktor Risiko Kebiasaan Merokok terhadap Kejadian Diabetes Melitus Tipe 2 di Puskesmas Purwokerto Selatan

Tabel 11. Uji Chi Square: Hubungan Kebiasaan Merokok terhadap Kejadian Diabetes Melitus Tipe 2 di Puskesmas Purwokerto Selatan

\begin{tabular}{|c|c|c|c|c|c|c|c|}
\hline \multirow{3}{*}{$\begin{array}{c}\text { Kebiasaan } \\
\text { Merokok }\end{array}$} & \multicolumn{7}{|c|}{ Kejadian DM Tipe 2} \\
\hline & \multicolumn{2}{|c|}{ Ya } & Tidak & \multicolumn{2}{|c|}{ Total } & \multirow{2}{*}{\multicolumn{2}{|c|}{$\begin{array}{c}\text { Sig. } \\
(p \text {-value })\end{array}$}} \\
\hline & $\mathbf{F}$ & $\%$ & $\mathbf{F} \quad \mathbf{c}$ & $\%$ & $\%$ & & \\
\hline \multirow{2}{*}{$\begin{array}{l}\text { Tidak } \\
\text { Merokok } \\
\text { Merokok }\end{array}$} & 30 & 46,9 & 11 & 17,2 & 41 & 64,1 & \multirow{2}{*}{0,007} \\
\hline & 9 & 14,1 & 14 & 21,9 & 23 & 35,9 & \\
\hline
\end{tabular}

Berdasarkan tabel 4.11 dapat dijelaskan bahwa responden dengan kebiasaan tidak merokok yang mengalami kejadian diabetes melitus tipe 2 sebanyak 30 orang (46,9\%), sedangkan yang tidak mengalami kejadian diabetes melitus tipe 2 sebanyak 11 orang $(17,2 \%)$. Responden dengan kebiasaan merokok yang mengalami kejadian diabetes melitus tipe 2 sebanyak 9 orang $(14,1 \%)$, sedangkan yang tidak mengalami kejadian DM tipe 2 sebanyak 14 orang (21,9\%). Hasil uji Chi Square didapatkan nilai signifikan $p$-value $=0,007(<\alpha=0,05)$. Hal ini berarti terdapat hubungan kebiasaan merokok terhadap kejadian diabetes melitus tipe 2 .

Hasil penelitian ini sesuai dengan yang dilakukan oleh (Fanani, 2020) didapatkan bahwa dari 52 orang responden yang merokok diketahui 39 orang $(75,0 \%)$ responden menderita diabetes melitus tipe II dan 5 orang $(9,6 \%)$ responden menderita diabetes melitus tidak tipe II, sedangkan responden yang tidak merokok diketahui 2 orang $(3,8 \%)$ responden menderita diabetes melitus tipe II dan 6 orang $(11,5 \%)$ responden menderita DM tidak tipe II. Faktor risiko merokok memiliki nilai odd ratio $=23.400$ yang artinya perokok memiliki risiko 23 kali.

Tabel 12. Nilai Odds Ratio (OR): faktor risiko kebiasaan merokok terhadap kejadian diabetes melitus tipe 2 di Puskesmas Purwokerto Selatan Kabupaten Banyumas

\begin{tabular}{lccc}
\hline \multirow{2}{*}{ Variabel } & $\begin{array}{c}\text { Nilai Odds } \\
\text { Ratio }\end{array}$ & \multicolumn{2}{c}{$\mathbf{9 5 \%}$ C.I for $\operatorname{Exp}(\boldsymbol{B})$} \\
\cline { 3 - 4 } & $\boldsymbol{E x p}(\boldsymbol{B})$ & Lower & Upper \\
\hline $\begin{array}{l}\text { Kebiasaan } \\
\text { Merokok }\end{array}$ & 4,242 & 1,433 & 12,563 \\
\hline
\end{tabular}

Berdasarkan tabel 4.12 dapat dijelaskan bahwa faktor risiko kebiasaan merokok terhadap kejadian DM tipe 2 diketahui dari nilai Odds Ratio (OR) yang ditunjukkan pada nilai $\operatorname{Exp}(B)$ yaitu 4,242 yang artinya bahwa kebiasaan merokok memiliki pengaruh sebesar 4,242 kali terhadap kejadian diabetes melitus tipe 2 .

\section{Kesimpulan}

Dari hasil penelitian dan uraian yang telah dipaparkan di atas bisa disimpulkan bahwa umur, jenis kelamin, obesitas, aktivitas fisik dan kebiasaan merokok menjadi faktor risiko kejadian Dm tipe 2 di wilayah kerja Puskesmas Purwokerto Selatan. 


\section{Daftar Pustaka}

Aune, D., Norat, T., Leitzmann, M., Tonstad, S., \& Vatten, L. J. (2015). Physical activity and the risk of type 2 diabetes: A systematic review and dose-response meta-analysis. European Journal of Epidemiology, 30(7), 529-542. https://doi.org/10.1007/s10654015-0056-Z

Dinkes Banyumas. (2020). Profil Kesehatan Kabupaten Banyumas Tahun 2019. Journal of Chemical Information and Modeling, 53(9), 52-53.

Evi, K., \& Yanita, B. (2016). Faktor-Faktor yang Berhubungan dengan Kejadian Diabetes Melitus Tipe II. Majority, 5(2), 27-31. http://juke.kedokteran.unila.ac.id/index.php/ majority/article/view/1073

Fanani, A. (2020). Hubungan Faktor Risiko dengan Kejadian Diabetes Mellitus. Jurnal Keperawatan, 12(3), 371-378. https://doi.org/10.32583/keperawatan.v12i3.7 63

Kabosu, R. A. S., Adu, A. A., \& Hinga, I. A. T. (2019). Faktor Risiko Kejadian Diabetes Melitus Tipe Dua di RS Bhayangkara Kota Kupang. Timorese Journal of Public Health, l(1), https://doi.org/10.35508/tjph.v1i1.2122

Perkeni (2015). Konsesus Pengelolaan dan pencegahan Diabetes Melitus Tipe 2 di Indonesia. Jakarta: PB. Perkeni

Sugiyono. (2012).Metode Penelitian Kuantitatif, Kualitatif. Bandung: Alfabeta 